Trastorno Alimentario del Sueño inducido por el hipnótico Zolpidem

\section{Zolpidem-induced sleep-related eating disorder}

\section{Sr. Editor:}

La obesidad se considera actualmente una epidemia y un problema de salud pública, por lo que identificar cualquier factor reversible es de suma importancia.

Los trastornos alimentarios nocturnos (TAN) son más comunes de lo que se suponía y cada vez son mejor reconocidos y diagnosticados ${ }^{1,2}$. La prevalencia de TAN fluctuaría entre 1 y $5 \%$ de la población ${ }^{1,2}$ y pueden distinguirse dos tipos: síndrome alimentario nocturno (SAN) y trastorno alimentario del sueño (TAS) $)^{1,2}$. Los pacientes con TAS ingieren alimentos durante la noche en estado de inconciencia parcial o total del episodio, habitualmente a las 3 horas de iniciado el sueño. El olvido de lo comido en la noche y el ingerir alimentos no usuales favorecen el diagnóstico de TAS. Estos pacientes refieren una necesidad automática de comer y no poder volver a dormir sin concretarlo. Los pacientes con SAN, en cambio, tienen buen recuerdo de lo sucedido, comen alimentos habituales y generalmente no tienen otros trastornos del sueño asociados. Además, la asociación con psicofármacos apoya más la presencia de TAS que de SAN ${ }^{1,2}$.

Existen asociaciones del TAS con otros cuadros relacionados al sueño, como síndrome de piernas inquietas y apnea obstructiva del sueño, que derivarían en insomnio y, secundariamente, a este trastorno alimentario. En el año 2002 Morgenthaler y Silber comunicaron por primera vez 5 casos de TAS en relación al uso de zolpidem, describiéndolo como un nuevo efecto secundario $^{3}$. El grupo de drogas llamadas Z (zolpidem, zaleplon, zopiclona, eszopiclona) son hipnóticos no benzodiazepínicos, de los cuales zolpidem es el más usado para la terapia del insomnio de conciliación, actuando como agonista en los receptores GABA-A $\mathrm{A}^{4}$. Hasta la fecha no existen más de 30 casos documentados en la literatura ${ }^{3,5,6}$. No verificamos ningún caso publicado en literatura de habla hispánica.

Efectos secundarios habituales asociados a zolpidem son la amnesia transitoria y el sonambulismo. Debido al frecuente uso de zolpidem y a los cada vez más prevalentes TAN que pueden resultar en obesidad y sus reconocidas complicaciones, consideramos de interés presentar un paciente que desarrolló un TAS en relación al uso de zolpidem:

Hombre, 49 años, ingeniero, portador de cardiopatia coronaria e hipertensión arterial tratado con clopidogrel $75 \mathrm{mg} /$ día y carvedilol $25 \mathrm{mg} /$ día. Cuando pesaba $132 \mathrm{~kg}$ desarrolló apnea obstructiva del sueño, se indicó un dispositivo de presión continua en la vía área (CPAP) que no toleró y luego de régimen estricto logró bajar $36 \mathrm{~kg}$ en 1 año, sin recidiva de la apnea. Se encontraba hacía 18 meses en tratamiento psiquiátrico por trastorno bipolar y crisis de pánico de larga duración. Recibía lamotrigina 200 $\mathrm{mg}$, clonazepam $2,5 \mathrm{mg} /$ día y zolpidem $10 \mathrm{mg} /$ noche, iniciado 14 meses previo al diagnóstico del trastorno alimentario. Luego de 4 meses de uso de zolpidem refirió aparición de una ingesta alimentaria excesiva en la madrugada, sin claro recuerdo de lo ingerido o su cantidad. Esto sucedía a diario, llegando a subir $20 \mathrm{~kg}$ en 6 meses. Su esposa relató que consumía grandes cantidades de dulces y mermeladas, alimentos que habitualmente no ingería y enfatizó que nunca antes se levantaba a comer de noche, incluso en el período en que llegó a pesar $132 \mathrm{~kg}$ y presentó apnea. Al despertar, el paciente no recordaba lo ingerido y permanecía con anorexia prácticamente toda la mañana. Su psiquiatra agregó topiramato 150 $\mathrm{mg}$ /día para contener la compulsión por comer, sin éxito. Se envió a evaluación neurológica en la cual no se observaron alteraciones, y se solicitó EEG estándar y post privación de sueño, ambos con resultados normales. Se redujo el zolpidem hasta suspenderlo en 10 días, se potenció con uso de sertralina $50 \mathrm{mg} /$ día y se observó progresiva mejoría del TAS. El paciente y su esposa refirieron luego de 2 meses una completa desaparición de los episodios de ingesta alimentaria nocturna, la que se mantiene a los 5 meses de seguimiento.

Si bien existen diferencias entre ambos trastornos alimentarios asociados al sueño, hay consenso en que tienen varias características comunes. Nuestro paciente tiene características clínicas concordantes con TAS ya que presenta amnesia del episodio, ingiere alimentos no habituales en su dieta y hay concomitancia con psicofármacos potencialmente inductores del trastorno, como zolpidem. La Tabla adjunta permite una aproxi- 
Tabla. Características Clínicas de los Trastornos Alimentarios Nocturnos (TAN)

\begin{tabular}{|c|c|c|}
\hline & $\begin{array}{l}\text { Síndrome Alimentario Nocturno } \\
\text { (SAN) }\end{array}$ & $\begin{array}{l}\text { Trastorno Alimentario del Sueño } \\
\text { (TAS) }\end{array}$ \\
\hline Momento de ingesta de alimento & $\begin{array}{l}\text { Después de la última comida y previo al } \\
\text { despertar definitivo }\end{array}$ & $\begin{array}{l}\text { Después del inicio del sueño y previo al } \\
\text { despertar definitivo }\end{array}$ \\
\hline $\begin{array}{l}\text { Nivel de conciencia durante la } \\
\text { ingesta }\end{array}$ & Totalmente vigil & Inconciencia a totalmente alerta \\
\hline $\begin{array}{l}\text { Consumo de alimentos inusuales } \\
\text { (incluso sustancias no comestibles) }\end{array}$ & Raro & Común \\
\hline Trastornos relacionados & $\begin{array}{l}\text { Obesidad, trastorno afectivo, abuso de } \\
\text { sustancias }\end{array}$ & $\begin{array}{l}\text { Sonambulismo, síndrome de piernas } \\
\text { inquietas, apnea obstructiva del sueño, } \\
\text { obesidad, trastorno afectivo }\end{array}$ \\
\hline Asociación con fármacos & Ninguno reportado & $\begin{array}{l}\text { Zolpidem, triazolam, olanzapina y } \\
\text { risperidona }\end{array}$ \\
\hline Tratamientos reportados & Sertralina & $\begin{array}{l}\text { Dopaminérgicos, topiramato, benzo- } \\
\text { diazepinas }\end{array}$ \\
\hline
\end{tabular}

mación más clara a estas formas de trastornos alimentarios del sueño. Otros fármacos involucrados, especialmente en TAS, son los antidepresivos tricíclicos, anticolinérgicos, litio, triazolam, olanzapina y risperidona ${ }^{1,2}$. No existe explicación clara acerca del mecanismo que subyace a esta complicación. La amnesia asociada a los eventos nocturnos, incluyendo sonambulismo o manejar automáticamente, se podrían relacionar con el efecto sedante del zolpidem. Otra posibilidad es que el despertar que lleva a la conducta parasómnica, ocurra durante el sueño lento profundo (etapas 3 y 4) y el paciente actúe en estado de confusión ${ }^{6}$.

Otra teoría es que existan "generadores de patrones cerebrales" para conductas de sobrevida, como movilizarse y comer. El zolpidem, al unirse a receptores corticales GABA causaría liberación de estos patrones ${ }^{6}$.

Normalmente durante el sueño REM y NREM el metabolismo de la glucosa cortical se reduce, lo que no ocurre durante el sueño inducido por zolpidem ${ }^{6}$. Esto apoya la teoría de que puedan activarse, anormalmente, algunos patrones asociados a conductas de sobrevida. Desde la neuroquímica se plantea, además, que en los casos de TAN existiría un desbalance de los sistemas serotoninérgicos (5HT) y dopaminérgicos. Esto explicaría la buena respuesta a sertralina en SAN y la respuesta favora- ble a dopaminérgicos en los casos de $\mathrm{TAS}^{2}$. Sin embargo, también se han descrito buenos resultados con serotoninérgicos, como en el caso presentado.

A pesar de que todas las benzodiazepinas son potenciales inductoras conductas de hiperfagia, zolpidem es considerada como neutral en la regulación del apetito ${ }^{2}$. Éste actúa activando vías gabaérgicas y se ha demostrado su influencia en la actividad de neuronas serotoninérgicas del núcleo del rafe (principal sitio productor de 5HT), inhibiendo sus descargas ${ }^{7}$. Estas neuronas, y su acción serotoninérgica, son importantes en la regulación del ciclo sueño-vigilia, de la ansiedad y del control del apetito a nivel hipotalámico ${ }^{7,8}$. Un estudio que evaluó la acción del zolpidem sobre las concentraciones de serotonina en diversas zonas cerebrales, en animales, mostró que puede disminuir la síntesis de serotonina en el hipocampo, ganglios basales y corteza frontal ${ }^{4}$. Planteamos la hipótesis que zolpidem podría inhibir la acción de la serotonina en el núcleo hipotálámico ventrolateral (vinculado al control del apetito) o a nivel de las neuronas del rafe que dan origen a la inervación serotoninérgica hacia regiones superiores.

Sugerimos que esta hipofunción serotoninérgica producida por zolpidem, podría explicar el efecto positivo de los serotoninérgicos en revertir el efecto secundario del hipnótico. 
En suma, creemos importante considerar en un paciente con un trastorno alimentario en horas de sueño, la posibilidad de estar inducido por un fármaco hipnótico como zolpidem. El manejo puede implicar la simple suspensión de éste, con una marcada mejoría de la sintomatología y calidad de vida del paciente.

Marcelo Miranda ${ }^{1}$, Daniel Seijas ${ }^{2}$, José Luis Castillo ${ }^{3}$, Carolina Pérez J. ${ }^{\text {Ia }}$ ${ }^{1}$ Departamento de Neurología, Clínica Las Condes. Santiago, Chile. ${ }^{2}$ Departamento de Psiquiatría, Clínica Las Condes. ${ }^{3}$ Departamento de Ciencias Neurológicas, Facultad de Medicina, Universidad de Chile. ${ }^{a}$ Psicóloga.

\section{Referencias}

1. Schenck C, Mahowald M. Sleep related eating disorders. Int J Eating Dis 1994; 15: 343-56.

2. Howell M, Schenck C, Crow S. A review of nightime eating disorders. Sleep Med Rev 2009; 13: 23-34.
3. Morgentahler T, Silber MH. Amnestic sleep-related eating disorder associated with Zolpidem. Sleep Med 2002: 3: 323-7.

4. Scatton B, Claustre Y, Dennis T, Nishikawa T. Zolpidem, a novel nonbenzodiazepine hypnotic. II. Effects on cerebellar cyclic GMP levels and cerebral momonamines. J Pharmacol Exp Ther 1986; 237: 659-65.

5. Schenck C, Coonou DA, Castellanos, et al. Zolpideminduced sleep-related eating disorder (SRED) in 19 patients. Sleep 2005; 28: A259.

6. Hoque RM, Chesson AL. Zolpidem-induced night eating disorder J Clin Sleep Med 2009; 5: 471-6.

7. Judge SJ, Young RL. Gartside SEl GABA (A) receptor modulation of 5-HT neuronal firing in the median raphe nucleus: implications for the action of anxiolytics. Eur Neuropsychopharmacol 2006; 16: 612-9.

8. Monti JM, Jantos H. The roles of dopamine and serotonin, and of their receptors, in regulating sleep and waking. Prog Brain Res 2008; 172: 625-46.

Departamento de Neurología, Clínica Las Condes. Santiago, Chile. E-mail: marcelomirandac@gmail.com

Los autores declaran no tener conflictos de intereses en este manuscrito. 